\title{
El Futuro de la Administración
}

The Future of Management

\author{
Pedro Alfonso Ramos Sánchez ${ }^{a}$, Noemi Vega Lugo ${ }^{b}$
}

\begin{abstract}
:
Management is in constant evolution and to be efficient it should take full advantage of their innovative capabilities, the importance of being an enterprise that work efficiently is not equal to operate with strategic efficiency, to achieve this is important to: Add collective wisdom and make an innovation agenda with a clear focus to measure innovation goals. The challenge is to use innovation to tie companies to human beings not the opposite.
\end{abstract}

Keywords:

Management, technological Innovations, knowledge management

Resumen:

La administración, una disciplina en constante evolución, implica para su eficiencia aprovechar al máximo sus capacidades innovadoras, la importancia de ser una empresa que trabaje de forma eficiente no es igual a operar con eficiencia estratégica, para lograrlo es importante: sumar la sabiduría colectiva y realizar una agenda de innovación con enfoque claro que mida las metas, el reto es atar a la innovación a los seres humanos y no al contrario.

Palabras Clave:

Administración, Innovaciones tecnológicas, gestión del conocimiento

\section{Reseña}

La primera parte del libro inicia haciéndose la pregunta: ¿Qué es lo que logra el éxito duradero de un negocio? Los autores dan respuesta añadiendo que: No es la excelencia operativa o los nuevos modelos de negocio, pero lo que si influye más es la administración de la innovación, es decir las nuevas formas de movilizar el talento, localizar los recursos y la construcción de estrategias, las empresas que han destacado y que han sobrevivido son las que generaron ventajas de largo plazo y que mantuvieron un proceso riguroso de administración de innovación, que fue lo que a muchas empresas les hizo falta.

La administración debe de ser más audaz no solo emplear el tradicional modelo centrado en el control y en la eficiencia ahora se tiene que poner énfasis en la capacidad de adaptación de las empresas y lograr a través de la creatividad poder llevar a las empresas al éxito. La clave está en ser innovadores en el más amplio sentido.

Esta obra cuenta con 272 páginas dividida en cuatro partes y once capítulos.

La primera parte habla de la importancia de la innovación, iniciando con la idea de que en la administración es difícil de percibir los cambios que se dan con el paso del tiempo, es decir son graduales pero después de un lapso pueden significar cambios dramáticos que hacen difícil imaginar cómo es que se va reinventando poco a poco hasta cambiar significativamente en las próximas décadas.

La administración es como un paradigma, cada vez que se alcanza un pico o cima descubrimos una mayor para escalarla.

En la actualidad es difícil pensar que una empresa que se fundó en 1903 - la empresa Ford Motor company estuviera fabricando más de medio millón de autos después de su primer década. La administración seguirá cambiando drásticamente como cambio durante los primeros años del siglo 20. El autor no solo está de acuerdo con esta idea sino que también dice que debemos hacer que esto suceda, los autores mencionan que si los humanos fuimos capaces de la organización

\footnotetext{
a Autor de Correspondencia, Universidad Autónoma del Estado de Hidalgo, Instituto de Ciencias Económico administrativas, ORCID: 00000003-3784-6061, Email: pedro_ramos3944@uaeh.edu.mx

${ }^{\mathrm{b}}$ Universidad Autónoma del Estado de Hidalgo, Instituto de Ciencias Económico Administrativas, ORCID: 0000-0001-5794-1168, Email: noemivl@uaeh.edu.mx
} 
industrial moderna, también podemos reinventarla. Siempre existen personas con ganas de transformar lo que es a lo que puede ser. Este libro es una herramienta que nos impulsa a imaginar cómo logra ser este proceso de cambio en la administración.

La administración de la innovación es algo que sustancialmente altera la forma en que se lleva el trabajo administrativo, o en que modifica las formas tradicionales de organización y de la misma forma haciendo avances en las metas organizacionales, sin duda es considerada en la actualidad como una de las ventajas más importantes que no deben de perder de vista las empresas, pues ahí es donde radica la permanencia y preferencia del mercado.

En los últimos 100 años La práctica de la administración tiene que ver con: Definir y programar objetivos, motivar y hacer un esfuerzo de alineación, coordinar y controlar actividades, desarrollar y asignar talento, acumular y aplicar el conocimiento, amasar y designar recursos, construir y nutrir relaciones y balancear e identificar las demandas de los interesados. Las recetas y rutinas que tienen que ver con la forma de operar de la administración incluyen: Planificación estratégica, presupuestar capital, administración de proyectos, contratación y promoción, entrenamiento y desarrollo, comunicaciones internas, administración del conocimiento, revisiones periódicas del negocio y medir el desempeño de los empleados. Actualmente administrar la innovación otorga poder, el liderazgo tecnológico siempre marca deferencia siendo el caso en las batallas de la antigüedad con la incorporación de los arcos con flecha, las pistolas o armas de fuego y ahora en la actualidad los cohetes dirigidos por láser en las guerras del golfo pérsico. En el campo de lo industrial y lo militar la lección es la misma. La administración de la innovación, sumar innovaciones cuenta mucho ya que es capaz de crear una ventaja competitiva.

Existen diversas formas de innovación cada una aporta beneficios para alcanzar el éxito, considerando los niveles más altos implican mayor valor de creación y de defensa competitiva, para poder involucrar al personal en el compromiso de la innovación los autores proponen que se debe de empezar desde la administración que debe de incluir la orientación hacia la innovación, partiendo de una innovación estratégica hasta aterrizarla a los productos o servicios y la operación. Véase Figura 1

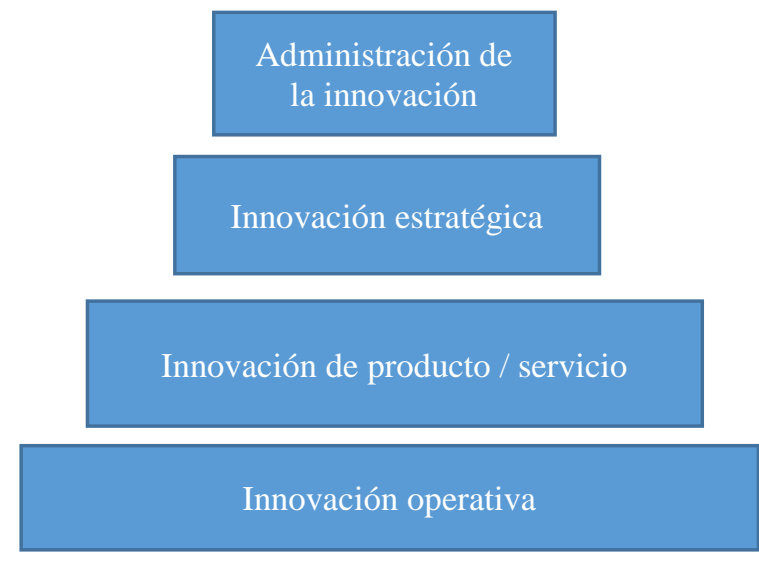

Figura 1 El apilamiento de la innovación. 1

Los autores señalan la importancia de que nunca se debe de perder el deseo de hacer las cosas de otra manera, se debe de crear un hábito por la innovación.

Para lograr lo anterior es necesario contar con una agenda para administrar la innovación donde hay que considerar: Ser audaz, con energía tomar la decisión de atender un problema que sea memorable, entender: ¿Cuáles son los retos de la compañía en el futuro?, ¿Cuáles son los actos que den balance a la compañía y los que no?, ¿Cuáles son las principales brechas entre el discurso y la realidad?, ¿Qué capacidades deben de incrustarse en la compañía?, ¿Qué es lo que indigna o frustra más en la compañía? Deben de existir acciones que lleven a la empresa a ser estratégica, que todos aporten innovaciones, compromiso en el trabajo en equipo, la idea es calibrar la agenda de innovación personal, buscando las causas de raíz.

Para los autores es mejor una persona con pasión que cuarenta interesadas. La pasión contribuye con hasta un $35 \%$ en la conclusión de un objetivo, destacando la creatividad, la iniciativa, el intelecto y la diligencia.

La segunda parte habla de la administración de la innovación en acción a través de la creación de una comunidad de propósito. La industria alimentaria en los supermercados estadounidenses son un buen ejemplo de donde los proveedores y comerciantes junto con los clientes tienen una comunidad de propósito, en donde se trabaja sintiendo que cada persona dirige un pequeño negocio, ejemplos destacados son señalados como la firma Whole foods empresa alimentaria de venta de productos orgánicos quien afirma que es como el Starbucks de los supermercados. Cada departamento es evaluado por sus resultados en ventas y en ganancias y es considerado como una unidad de negocio, hay libertad para que el personal influya en la contratación y son motivados por sus ventas en la nómina.

Un aspecto importante es el de la confianza, como ejemplo todos tienen acceso a ver los resultados de cuánto ganan y cuanto es su impacto en la empresa, de esta forma se impide pagar más a los amigos del gerente o que existan favoritismos.

Otro aspecto es la equidad, en la empresa Whole foods la atmosfera de trabajo es la sensación de formar parte de una comunidad en lugar de un lugar de trabajo donde existan las jerarquías, Los valores que son señalados como distintivos en Whole Foods, están representados desde el lema que dice que ofrecen a la gente mejores cosas para comer, transforman el consumismo en capitalismo con consciencia, los productos que venden son orgánicos, tienen sus propias plantas productoras de mariscos y se preocupan por dar una muerte sin dolor a la hora de sacrificar a los animales que venden, invierten en energía eólica y en ahorro de energía, manifiestan su pasión por lo sustentable y por lo rentable, la comida que venden es libre de pesticidas y no contaminan el ambiente, los clientes aprecian la responsabilidad social de la empresa, establecen principios como: amor, comunidad, autonomía, igualdad y transparencia, 
libertad, responsabilidad competencia y no dejan de preocuparse por la comunidad.

La tercera parte se centra en crear una democracia de innovación a través de una hoja de ruta, donde se asignen a los empleados metas, se propone el renunciar a las estructuras jerárquicas arcaicas, donde existan patrocinadores y no jefes, que cada individuo tenga compromisos y no tareas. En esta parte es considerable hacer y atender las siguientes preguntas clave: ¿Cómo puedes enrolar a tus empleados en el camino a la innovación?, ¿Cómo hacer que las prácticas administrativas actuales no estrangule a la innovación? y ¿Cómo crear tiempo y espacio para la innovación cuando todos están ocupados? Estas interrogantes pueden ser atendidas considerando que se puede aspirar a tener una ventaja que sea evolutiva, es decir que no permanezca estática en el tiempo si no que gradualmente se convierta en escalable. Para lograr esto los autores argumentan: Tener una proyección y disciplina en el proceso creativo, buscar principios administrativos actuales, aprovechar las crisis para realizar cambios ya que estas son a veces necesarias, emplear a un líder fuerte para estimular los cambios y considerar que estos cambios deben de comenzar desde arriba.

Considerar la importancia de que operar eficientemente no es igual a operar con eficiencia estratégica, para esto es importante: Sumar sabiduría colectiva y realizar una agenda para la innovación con un enfoque claro, que se puedan medir las metas de innovación para la mejora.

La parte cuatro plantea construir el futuro de la administración considerando como el eje más importante el logro de la administración de la innovación, que es una tarea permanente donde deben de conjugarse el esfuerzo amplificado, la pasión, la creatividad, la iniciativa, el intelecto, la diligencia y la obediencia para sumar un esfuerzo agregado y lograr deseada administración de la innovación. El reto actual después de la era industrial es crear empresas que empaten o que estén adaptadas a los seres humanos y no de forma contraria, he ahí el reto de las nuevas empresas.

\section{Referencias}

[1] Hamel G, y Breen B. The Future of Management, Harvard Business School Press. Boston: Mass, 2007:32. 